\title{
PAMONHA: TRAÇO CULTURAL NA ALIMENTAÇÃO DE TAUARI
}

\author{
Savana Cristina Lima Cardoso ${ }^{1}$ \\ Daniel dos Santos Fernandes ${ }^{2}$
}

O uso de imagens em pesquisas acadêmicas tem levantado bastantes questões no que diz respeito a importâncias do uso das imagens em pesquisas, uma vez que por meio da imagem a memória passa a ser revisitada, pois a imagem evoca uma série de imagens, formando dessa forma uma espécie de narrativa visual. Boris Kossoy (2009 p.161) alega,

O fragmento da realidade gravado na fotografia representa o congelamento do gesto e da paisagem, e, portanto, é a perpetuação de um momento, em outras palavras, da memória: memória do indivíduo, da comunidade, dos costumes, do fato social, da paisagem urbana, da natureza. A cena registrada na imagem não se repetirá jamais.

A imagem assume um papel importante, sendo desta forma vista como fonte de documentação, permitindo desde modo que a imagem seja congelada naquele momento em que foi registrada, nesse sentindo a imagem representa a perpetuação de um momento, em outras palavras, da memória, seja ela individual ou coletiva. Baseado nessa perspectiva, o presente ensaio busca valorizar as imagens como narrativas visuais, capazes de revelar saber e conhecimento na Amazônia paraense.

A pesquisa foi realizada em uma vila chamada Tauari - município de Capanema/PA, nela acompanhei o processo da feitura das pamonhas derivada do milho, sendo que a feitura delas foi feita no roçado ${ }^{3}$ de milho de uma senhora chamada Francisca Lima e de seu filho Enoque Lima, família está que reside na comunidade de Tauari. O roçado de milho do qual visitei fica distante da casa dos donos, cerca de $2 \mathrm{~km}$ de distância da casa deles, e pelo fato da distância, eles construíram uma barraca provisória para passarem o dia quando for necessário.

O processo de feitura das pamonhas foi feito pela dona Francisca e seu Enoque, nesse caso a tarefa de fazer as pamonhas é dividida entre eles, sendo que o papel do homem é primeiro colher o milho, e logo em seguida descascar. E para que fique melhor de tirar a casca do milho, ele corta a cabeça do milho com um facão, assim fica mais fácil de descascar,

\footnotetext{
${ }^{1}$ Discente do Programa de Pós-Graduação em Linguagens e Saberes na Amazônia (PPGLSA) - Universidade Federal do Pará - Campus Universitário de Bragança. Email: savana292010@ hotmail.com

${ }^{2}$ Este texto não se configura como um trabalho etnográfico estrito. A partir das experiências em campo dos autores, em estudos e investigações em comunidades pesqueiras e ribeirinhas das microrregiões do Baixo Tocantins, Salgado e Bragantina, no Estado do Pará (Brasil), no período de 2000-2014, pretende-se o desenvolvimento de reflexões de caráter mais teórico acerca dos conceptos de saber e conhecimento, sem, no entanto, deter-se em exaustivas descrições e narrações etnográficas, o que não é apanágio da proposta. Vide Fernandes (2007 e 2011) e Fernandes e Silva Júnior (2015). 2 Professor e Coordenador de Pesquisa das Faculdades Ipiranga (PA), Doutor em Antropologia (Universidade Federal do Pará, 2008), Associado Efetivo da Associação Brasileira de Antropologia. Email: dasafe@msn.com .

${ }^{3}$ A roça diz respeito a um terreno em que eles usam para o cultivo da mandioca, feijão, arroz, milho, entre outros, em outras palavras o roçado faz referencia uma área para o cultivo de plantações.
} 
depois que ele corta a cabeça do milho, ele passa tirar as cascas com as mãos. Depois de descascadas, o homem leva o milho para a barraca, vale ressaltar que essa barraca é coberta com palhas, a barraca é bem simples, não é coberta nos lados, mas serve para proteger as pessoas do sol e da chuva. Essa barraca fica bem próxima ao milharal, e foi justamente nessa barraca que eles prepararam as pamonhas.

Após seu Enoque alocar o milho para a barraca, cabe à mulher o papel maior da feitura das pamonhas, a senhora senta-se em um pequeno banco para relar o milho até se transforma numa massa homogênea. É importante mencionar que o ralador é feito da lata de óleo, funciona dessa forma como uma espécie de reciclagem.

Após o milho ser transformado em massa, a senhora começa a despejar a massa numa espécie de saco confeccionado da própria casca de milho, depois que ela despeja a massa nesse recipiente, ela amarra com um fio feito também da casca do milho, é necessário amarrar esse saco, para que assim a massa não derrame no momento do cozimento. Depós de amarrados, as pamonhas são colocadas numa panela grande junto com água, sendo que o cozimento dura cerca de 30 minutos. Após esse processo de cozimento, as pamonhas são tiradas da panela com água, e colocadas numa vasilha prontas para serem saboreadas.

O processo de feituras das pamonhas se tornou um ritual e uma tradição para essas pessoas, uma vez que a pratica da preparação das pamonhas é comum entre eles. A pamonha dessa forma se tornou parte da culinária dessas pessoas, representando símbolos de uma prática cultural, que por sua vez é concebido pela alimentação.

\begin{abstract}
Dessa forma a perspectiva é a da História da Alimentação e o alimento será tomado como prática cultural, ou seja, como sistema de valores que estrutura a percepção e a postura dos indivíduos no cotidiano e, portanto, é fundamental no que se refere à sua identidade e à identidade de seu grupo, ainda que passe despercebido pelos sujeitos (CERTEAU; GIARD; MAYOL, 2000).
\end{abstract}

A culinária dessa forma é vista como um dos modos pelos quais as identidades assumem a materialidade. A comida típica não é qualquer comida; representa experiências vividas, representa práticas culturais, representa o passado e, ao fazê-lo, o coloca em relação com os que vivenciam o presente. E ainda manifestam a potência dos saberes da cultura da Amazônia paraense. 


\section{REFERÊNCIAS}

CERTEAU, Michel de; GIARD, Luce; MAYOL, Pierre. A invenção do cotidiano: artes de fazer. v. 2. Petrópolis, RJ: Vozes, 2000.

KOSSOY, Boris. Fotografia \& História. 2a Ed. São Paulo: Ateliê Editorial, 2009.

LE GOFF, Jacques. História e memória. Tradução Bernardo Leitão. Campinas, SP Editora da unicamp, 1990, p. 423. 


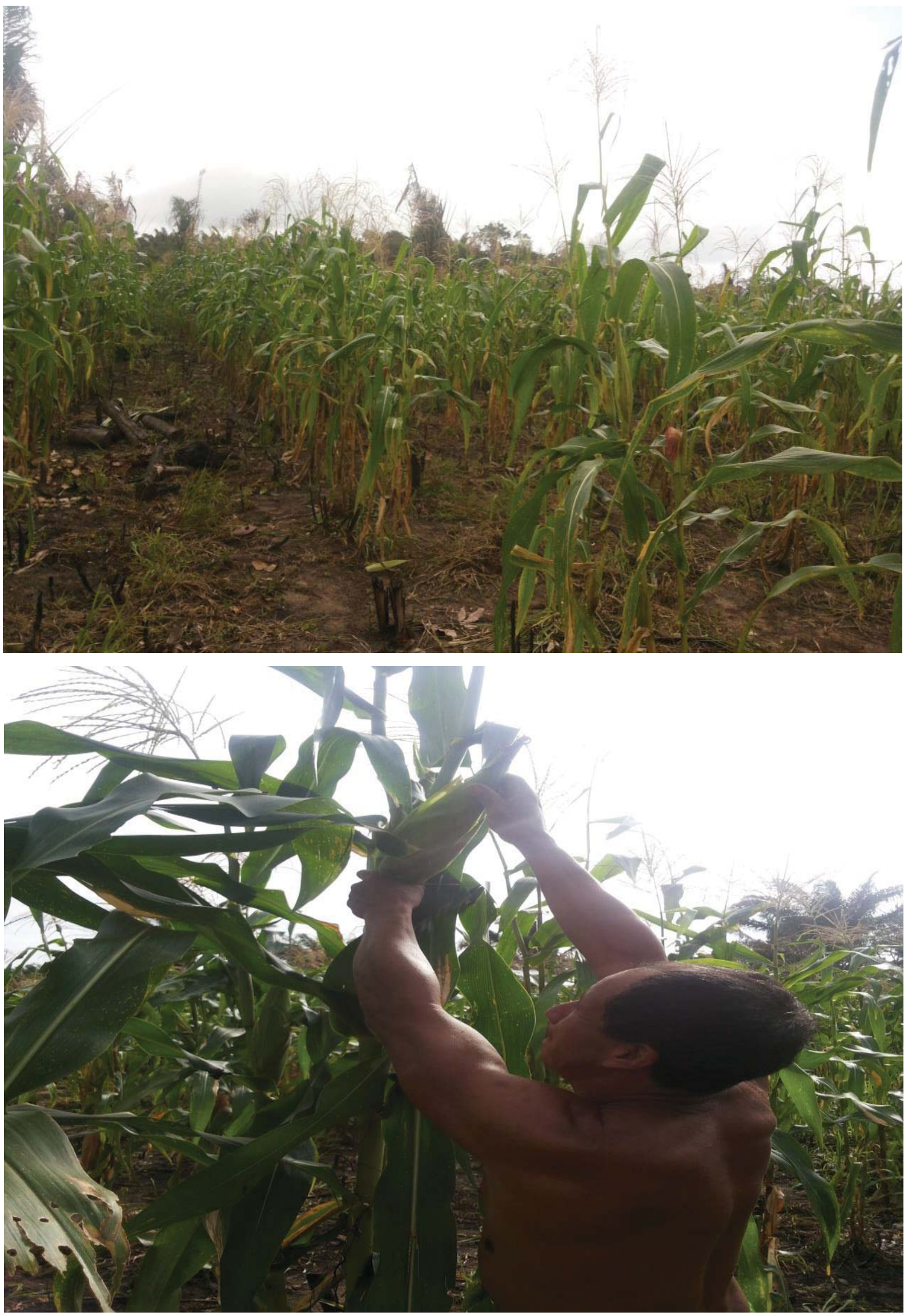



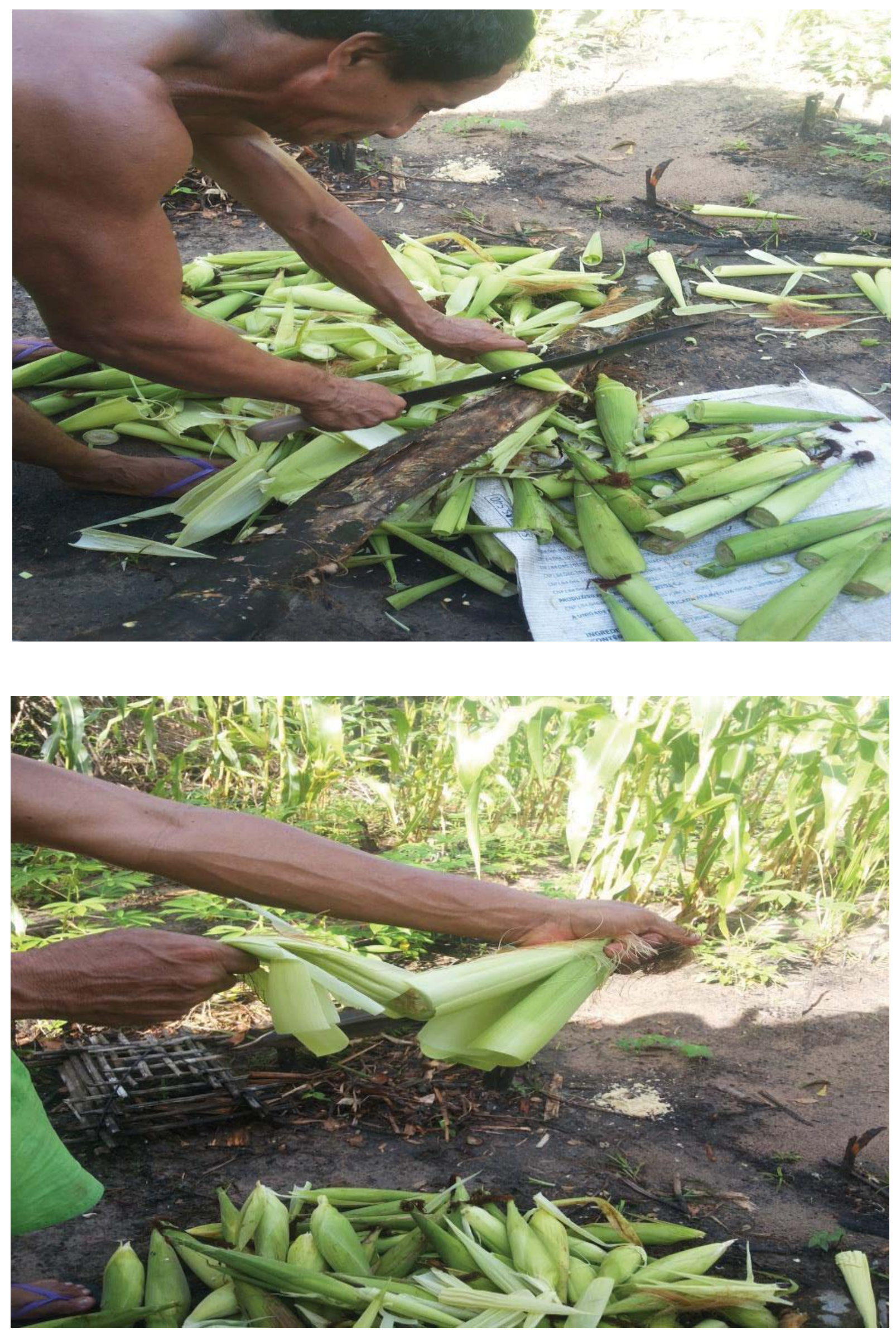

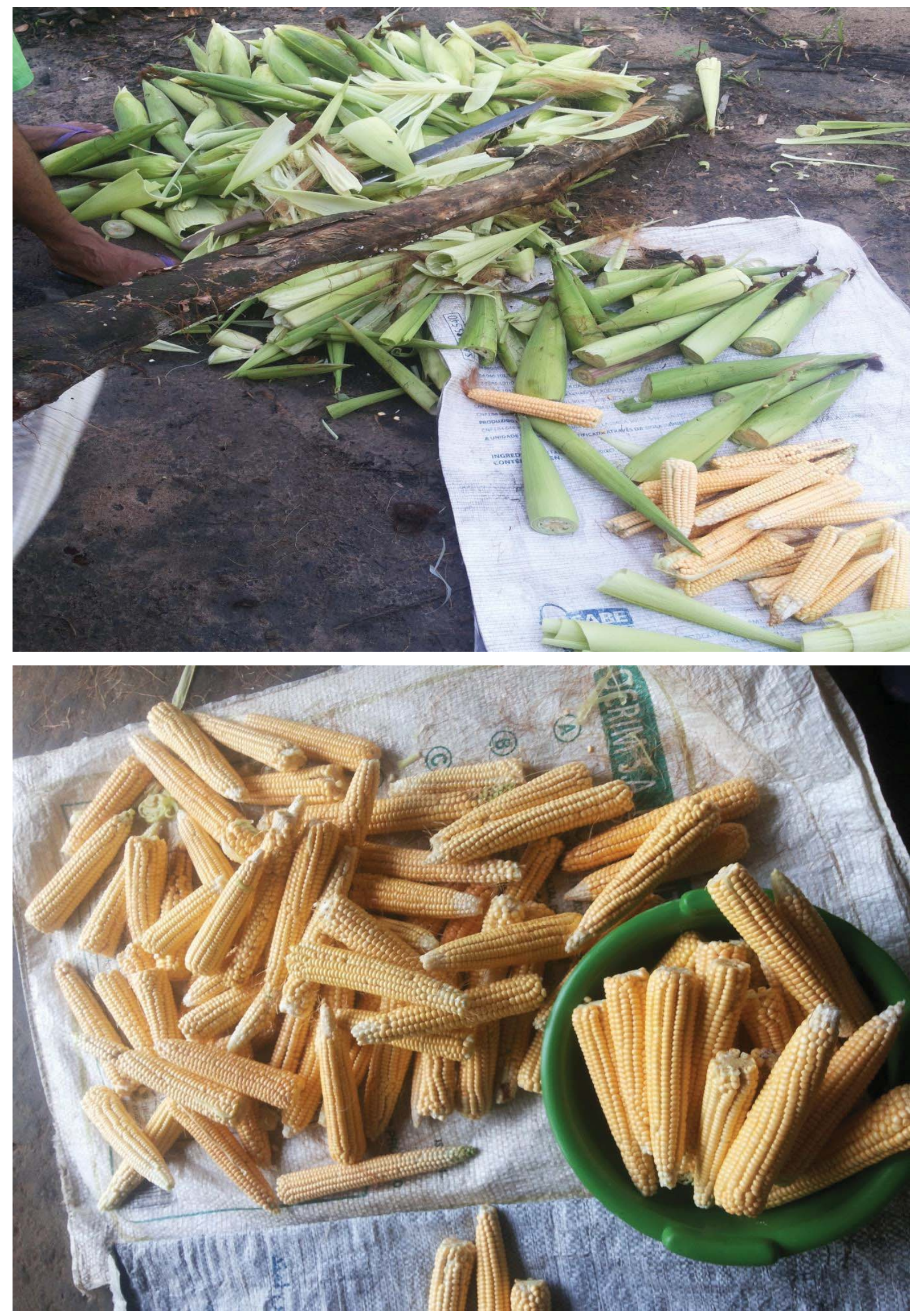

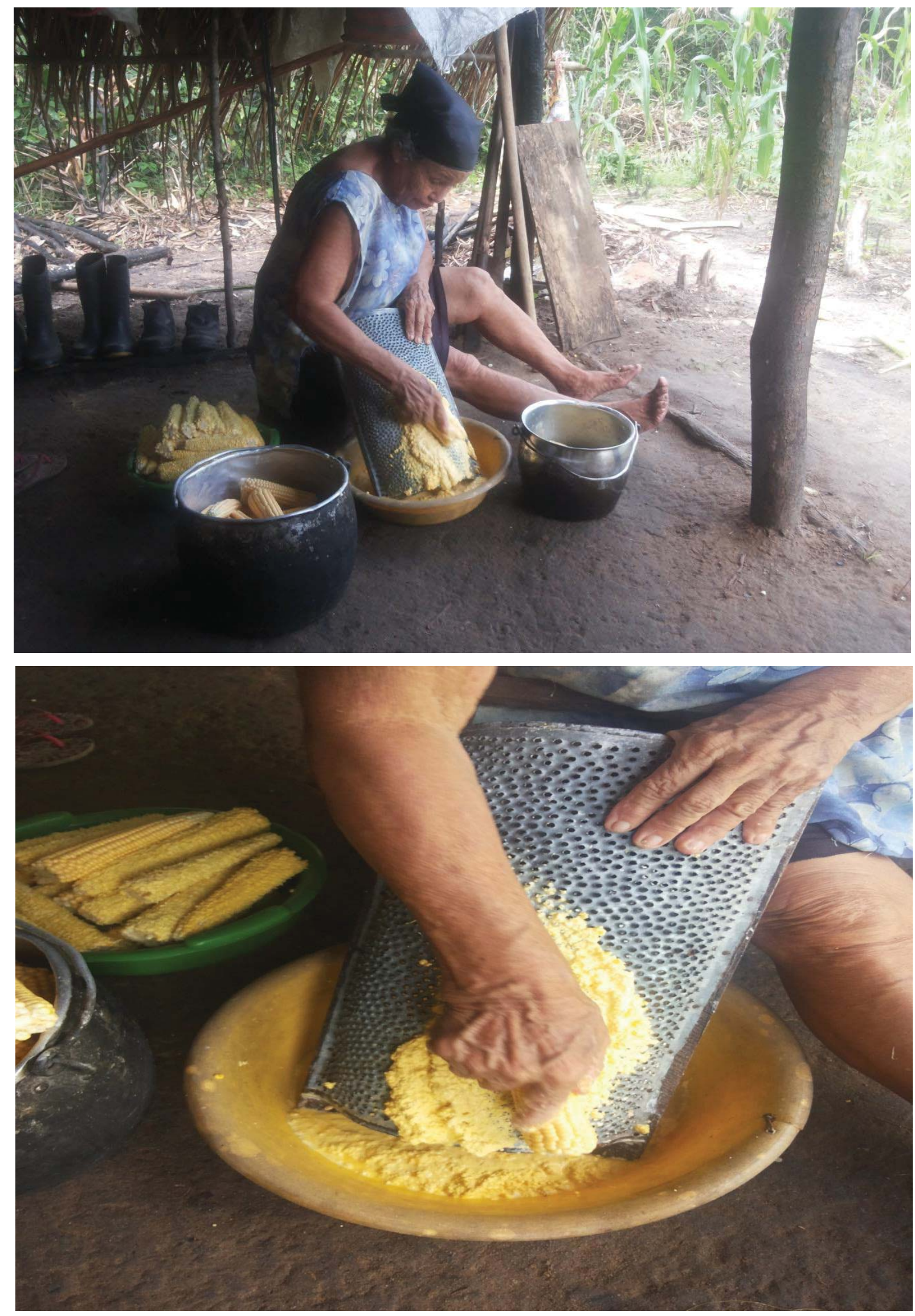

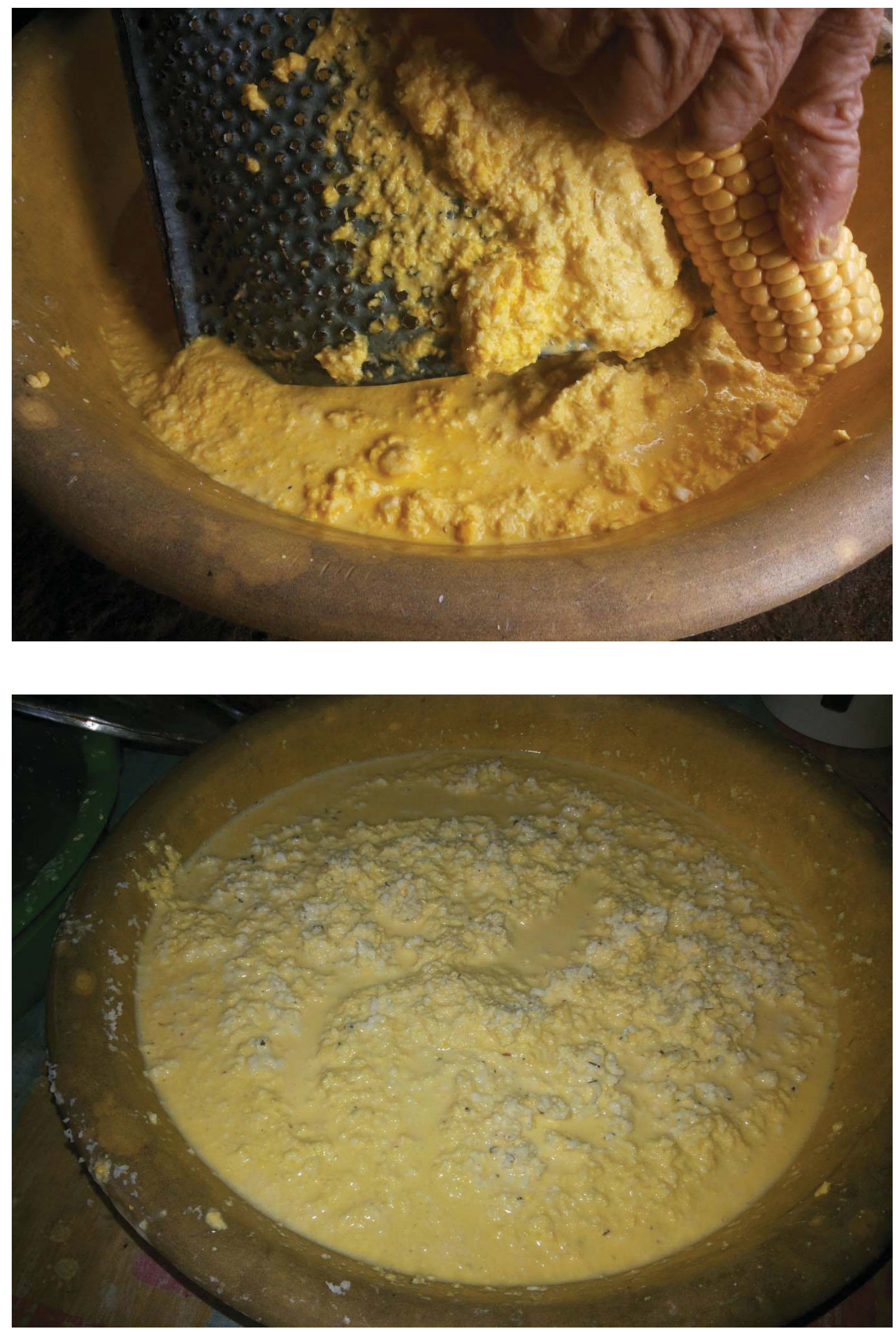

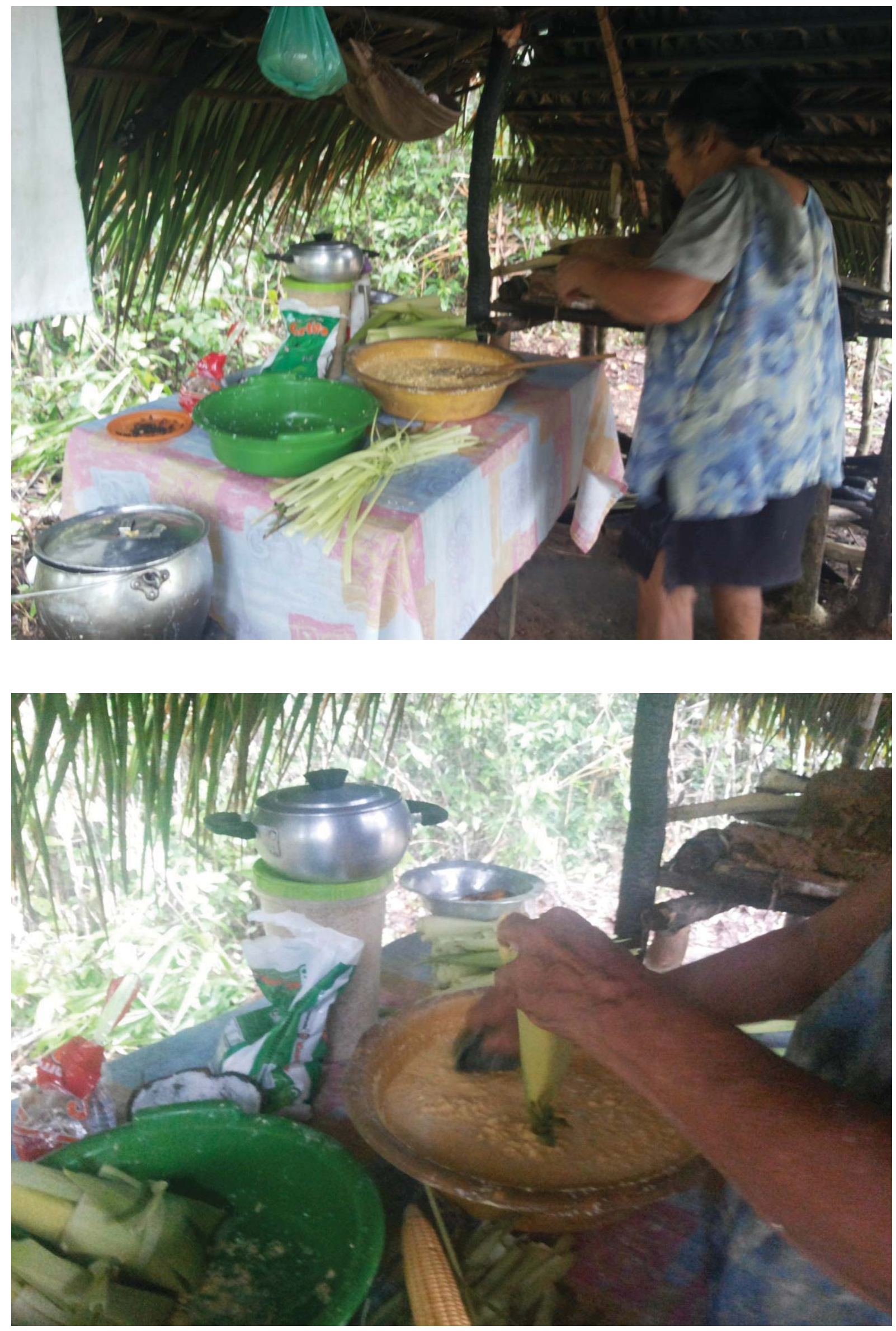

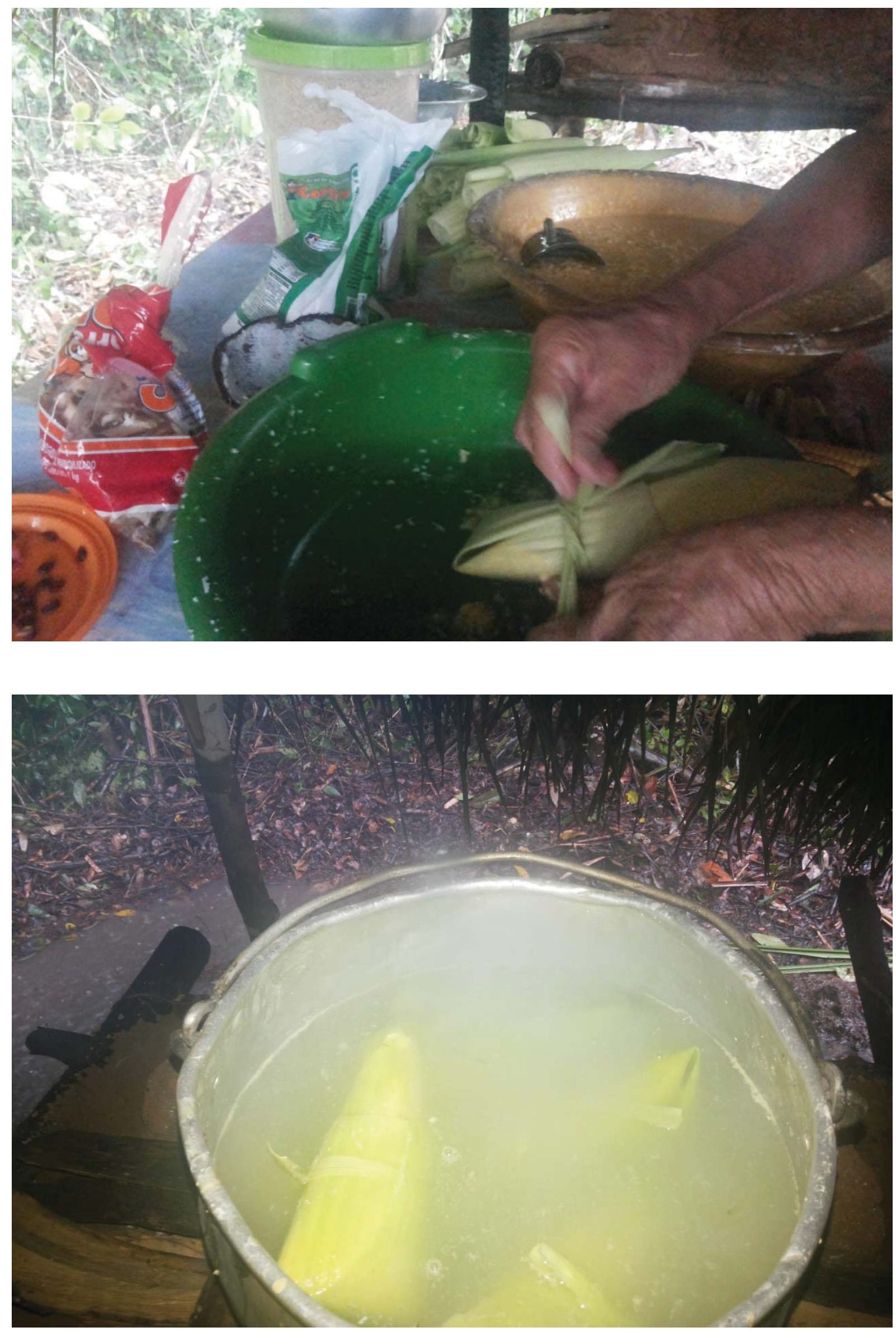


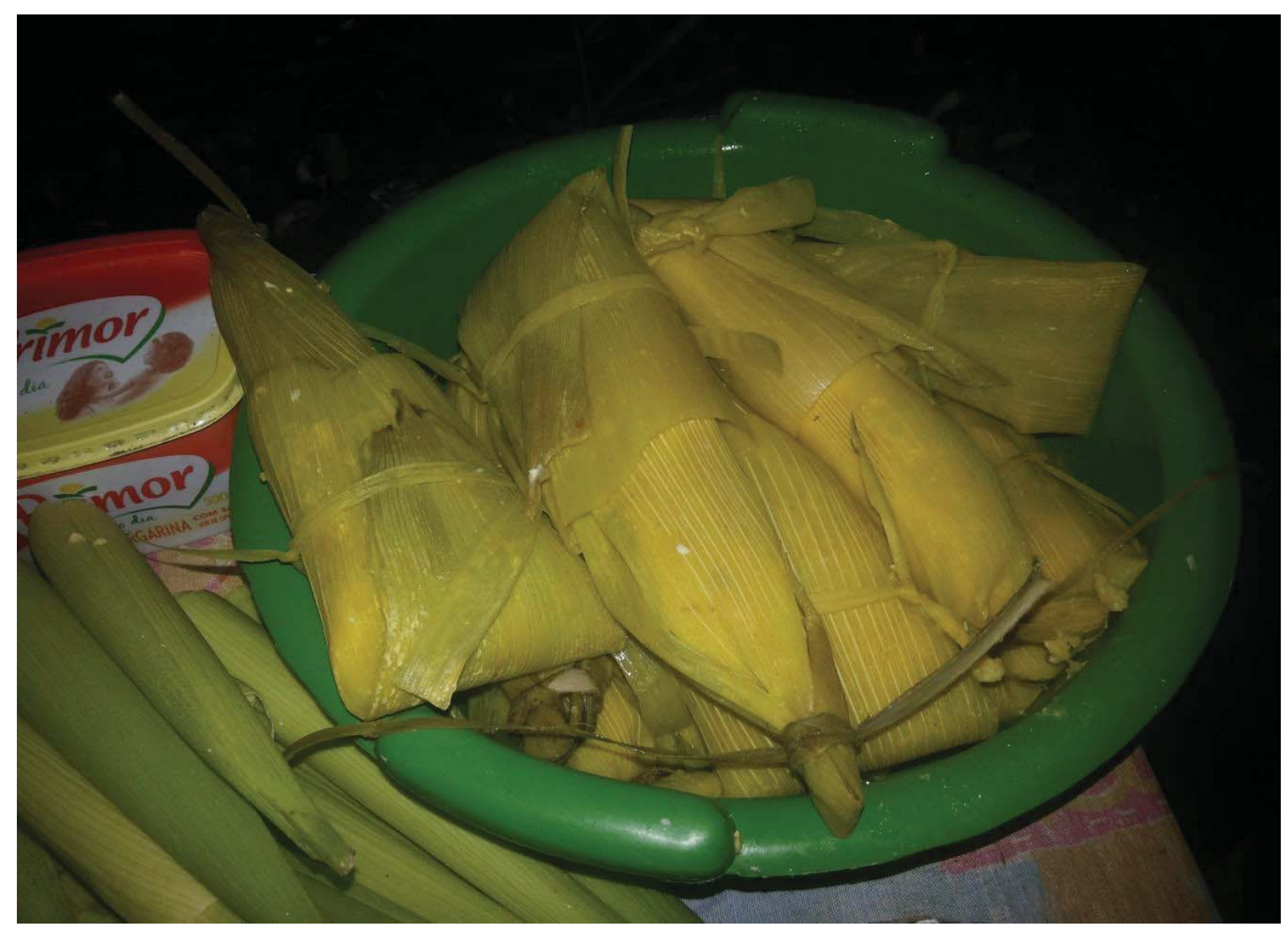

